\title{
The Harkive Project: Rethinking Music Consumption
}

\author{
CRAIG HAMILTON, Birmingham City University
}

\begin{abstract}
This report is an overview of my progress through a 3-year, AHRC-funded doctoral research project looking at the changing nature of Popular Music consumption, with a particular focus on digital technologies. I am undertaking this project within the School of Media at Birmingham City University in the United Kingdom. After providing an overview of the project and work completed so far, I will then highlight some of the key challenges I am facing now that I have reached the halfway point in my studies, before outlining some of the ways I am seeking to address these. I will end this report with a short reflection on the process of working towards a PhD.
\end{abstract}

\section{KEYWORDS}

Popular Music; Big Data; Social Media; Audiences

\section{Introduction}

Many of the ways in which popular music is produced, distributed and consumed have altered considerably over the last 15-20 years, and largely as a result of digital technologies. Having reached an all-time peak in the late 1990s, based in large part around the popularity of the CD format, revenues for recorded music began to drop rapidly shortly thereafter, and continued to fall throughout the first decade of the $21^{\text {st }}$ century. A significant contributing factor in this decline was the disruptive emergence of Peer-to-Peer services such as Napster, and an industry-wide inability to react to the changes in consumption behaviour such technologies afforded. Rights holders have since then slowly established new 'loci of exchange' (Burkart 2014) in an attempt to re-exert a degree of control over what is an increasingly complex musical landscape, but it was not until 2013 that global recorded music revenues rose again for the first time this century. Further to this, in 2014, an important tipping point was reached, when revenues from digital formats (downloads, streams) overtook those derived from physical products (CDs, vinyl records) for the first time. 
Two important consequences of this shift from physical to digital primacy have been a shift in the political economy of recorded music, with technologists such as Apple and Google now occupying powerful positions in the supply chain. A second is the growing importance of and industrial reliance on the data that is generated by and about the experience and behaviour of listeners, which has potential consequences in and outside of the field. The changes outlined above suggest that an enquiry into the evolving nature of the popular music listening experience is therefore timely.

\section{The Harkive Project}

My primary means of investigating music consumption is through The Harkive Project (www.harkive.org), an online, crowd-sourced method of collecting stories and data from music listeners about the detail of their experience. The project runs on a single day each year and invites people to tell the story of their music listening on that day. Participants are requested to focus less on the 'What' they listen to (i.e. the songs and artists), and instead on considerations of 'How', 'Where' and 'Why' their listening occurs. This necessarily switches focus from more traditional quantitative popular music metrics (sales, chart positions, and so on) and instead generates qualitative data that describes individual interactions with technologies, formats, interfaces, locations, motivations for listening, as well as introducing an element of reflexivity regarding their experience as a whole.

The Harkive Project was initially developed as part of my MA in Music Industries studies at BCU, undertaken on a part-time basis between 2011-2013. It was always my intention that the project would have a life beyond my MA, and indeed it was my hope to establish Harkive as an annual event in the vein of Record Store Day and other music/cultural events. Beyond this, however, my expectation regarding success (in terms of the number of participants) was modest. It was therefore hugely pleasing and somewhat surprising - following a 6-week DIY promotional campaign - that on $9^{\text {th }}$ July 2013, Harkive proved very popular in the online space. It became the number 1 trending topic on Twitter in the UK, received coverage in media outlets across the world, and eventually gathered stories from over 2,500 people. I have a distinct and very vivid recollection from that day, of being sat alone at home in front of my computer, watching the numbers rise and rise, and thinking: "This is out of my control". It was equally exhilarating and disconcerting.

Following this initial success, which contributed to my passing the MA with a distinction, I was encouraged by tutors and colleagues with the Birmingham Centre for Media and Cultural Research ( $\underline{\mathrm{BCMCR}})$ to apply for the first round of the newly created AHRC-funded Midlands3Cities Doctoral Training Scheme. Following a seemingly endless period during which I drafted and then re-drafted my application, I was fortunate enough to be chosen as one of 80 Arts and Humanities students in the 2014 cohort. I commenced my studies at BCU in September of that year and at the 
time of writing this report I am approximately halfway through my proposed 3-year research project.

Harkive has run a further two times in the interim, on single days in July 2014 and 2015. Despite concerns on my part that 2013 may have been a freak occurrence, it has, I'm pleased to say, been equally successful in subsequent years - even briefly achieving number 1 Twitter trending status again on both occasions - and in 2015 was the subject of radio features on numerous BBC radio outlets, including Radio 4 Today, The World Service and 5Live Drive. I have also been fortunate to have been invited to speak about Harkive at numerous conferences, both academic and commercial/technology focused, including the ASI Radio Conference (Madrid, 2014), Music Tech Fest (London, 2013), IASPM (Cork, 2014), The Royal College of Music (London, 2015) and at specific research seminars at Cardiff University (Digital Social Research Group 2015) and at my host institution. Meanwhile, the number of responses from music listeners in the 'Harkive' is now close to 10,000, and therein lies the main methodological challenge of my $\mathrm{PhD}$ project.

\section{Limitations \& Challenges}

The main challenge of my $\mathrm{PhD}$ project thus far has to work towards devising a method of analysis that is robust enough to enable me to make a useful contribution to knowledge in the field of Popular Music studies. The nature of the data collected (tweets, images, audio clips, long-form essays, and so on) makes this particularly challenging, and it seems likely at this point that many of the 'standard' academic methodologies used in Popular Music Studies will not be fit for purpose as standalone solutions. In addition to this, and given the increasing reliance and focus on data within industrial circles, I need to address a key limitation in my own skills set, which I have summarised thus:

"I'm a reasonably tech-savvy media scholar, but I'm not a Data Scientist, or a coder. Yet, here I am, building a PhD research project that is increasingly data-heavy, and, moreover, relying on that data for my thesis"

In order to address this I have been engaged in a period of self-directed study around coding and other 'data science' skills, making reasonable progress in terms of my use of ' $R$ ' and other analytical tools. I am mindful, however, that I am operating within a limited timeframe and am conscious that outside assistance and further training will be required if I am to realise the potential held within my data. My training will shortly take on a more formal approach when I will participate in some intensive courses related to coding, and I have also been actively building a network of contacts within what can broadly be described as the data science community, and within academic institutions where cross-disciplinary approaches to data analysis are being 
developed. My aim is that, as my own skills set develops in this area, I will be able to meet with collaborative partners on something approaching useful, common ground.

The end result of this process will be to unlock what I see as the huge potential for analysis, enquiry and further research, based on both the data set I am collecting on an on-going basis, and also in the 'real-time' data generated by music listeners worldwide on a daily basis. In short, as many elements of the experience of music listeners are increasingly situated and recorded in data-driven environments (interfaces, social networks, and so on), there exists a hitherto unprecedented opportunity to study that experience as scale.

Based on this intention, and running alongside my work in terms of expanding my technical skills and network, I have also undertaken considerable work in engaging with the emerging body of academic literature that has arrived in the wake of digital technologies. Due to the speed and voracity of growth in this area, issues and questions related to data protection, use, monetisation, ownership, access, surveillance, storage, and archiving are of growing interest to academics in a number of fields, and Housley et al (2014) provide a great overview here. One result of this engagement has been the development of a conceptual model of 'Big Data' technologies, that is enabling me to gain greater understanding of how such technologies function on practical and ethical levels, and thus how they may potentially impact upon listener experiences.

Based on a reading of Michel de Certeau's (1984) work around everyday life in the city, and taking a heavy steer from Latour (2005) in a process of 'following the actors themselves' (in the sense that both the listeners and the technologies/interfaces can be conceived as such), I am aiming to combine a traditional approach with emerging data science methods in order to juxtapose the qualitative data collected by Harkive with the results of quantitative data collected about music listeners, particularly in terms of how these manifest themselves in interface design, curational technologies, and so on. A desirable outcome from this process would be the development of a hybrid methodology, one that is capable of not only making sense of the Harkive data, and thus listener experience, but also one that has potential applications in other fields.

\section{The Day-to-Day Reality}

As almost certainly anyone who has completed a $\mathrm{PhD}$ project will be able to empathise with, I must report that I often encounter a feeling of huge disconnection between the aims and objectives I have described above and the day-to-day realities of developing my project. Readers in a similar stage of their projects to me will, I feel certain, know this feeling well. I keep a weekly production diary of my progress (something I began during my MA studies), and entries can veer wildly from desolate crises of confidence to bullish reports of breakthroughs. Coupled with this, the 
extreme lows can sometimes follow a period when I have worked solidly for 40 to 50 hours, whilst the breakthroughs can occur during a walk in the park with my dogs: the ratio of effort to progress can be maddeningly skewed, and the ratios are subject to change without warning. This process is every bit as difficult and challenging as I had been warned that it would be.

It is, however, also a fascinating and highly stimulating one. Following over 20 years working in various roles within the music and technology industries (peppered with some less than rewarding roles along the way!), the opportunity to engage with my interest and passion at such a deep level is something that I never really thought would be possible, and as such I am attempting to grasp this chance with both hands. I am hugely grateful to BCU and the Midlands3Cities scheme for such an opportunity and I hope I can make good on their faith in me.

\section{Harkive 2016}

If you are interested in The Harkive Project and would like to contribute your story, the project will run for a $4^{\text {th }}$ time on Tuesday $19^{\text {th }}$ July 2016. Details about how you might do this, along with on-going progress reports about the project, will be posted to the project website: www.harkive.org, or you can follow @ harkive on Twitter.

If you have any questions about the project, or would like to discuss collaboration, please feel free to email info@harkive.org

\section{References}

Burkart, P. (2014). Music in the Cloud and the Digital Sublime. Pop. MUSIC Soc. 37, 393-407. doi:10.1080/03007766.2013.810853

De Certeau, M. (1984). Walking in the City.

Housley, W., Procter, R., Edwards, A., Burnap, P., Williams, M., Sloan, L., Rana, O., Morgan, J., Voss, A., Greenhill, A., (2014). Big and broad social data and the sociological imagination: A collaborative response. Big Data Soc. 1, 2053951714545135.

Latour, B., (2005). Reassembling the social-an introduction to actor-networktheory. Reassembl. Soc.- Introd. Actor-Netw.-Theory Bruno Latour Pp 316 Foreword Bruno Latour Oxf. Univ. Press Sep 2005 ISBN-10 0199256047 ISBN-13 97801992560441.

Craig Hamilton is a currently a $\mathrm{PhD}$ student at the School of Media at Birmingham City University. He has worked in music retail, the live music sector, digital distribution and as a musician and songwriter during his 20 -year involvement in the 
music industries. Alongside his studies and teaching at BCU, Craig also works as a consultant for a number of independent record labels and artists, and runs the successful music blog, Rock and Roll Tedium.

Email: craig.hamilton@bcu.ac.uk 